\title{
Redox reactions in the course of sorption onto minerals: cerium vs. plutonium.
}

\author{
ANNA ROMANCHUK, TATIANA PLAKHOVA, \\ ANASTASIIA KONYUKHOVA AND STEPAN KALMYKOV \\ Lomonosov Moscow State University \\ Presenting Author: romanchuk.anna@gmail.com
}

Currently, many countries are developing programs to rehabilitate previously radionuclides contaminated territories, which requires information on their migration routes in the environment. At the same time, data on speciation of radionuclides are needed for the long-term safety assessment of geological repositories of radioactive waste. The migratory behavior of radionuclides, their bioavailability, and, consequently, the potential danger are controlled by their species under environmental conditions where reactions with natural components (inorganic minerals and natural organic matters) are of paramount importance.

Plutonium is one of the main elements whose chemical behavior remains poorly predicted because of its complex chemical properties. The absence of a single thermodynamic model describing plutonium's behavior limits the successful prediction of its migration in the environment. One of the unique properties of plutonium is its ability to be present in 4 different oxidation states $(\mathrm{Pu}(\mathrm{III}), \mathrm{Pu}(\mathrm{IV}), \mathrm{Pu}(\mathrm{V})$, and $\mathrm{Pu}(\mathrm{VI}))$. During the last 15 years, several examples of redox reaction during plutonium sorption onto minerals have been presented in the literature, for example, ${ }^{1-4}$. However, a full understanding of the mechanisms of the reactions taking place and thermodynamic descriptions have not yet been achieved.

To create a general model for such type of interaction, we study the behavior of not only plutonium but also of its chemical analog - cerium. The use of cerium as analog, on the one hand, simplify the systems under study, since it may presents only on two oxidation state: $\mathrm{Ce}(\mathrm{III})$ and $\mathrm{Ce}(\mathrm{IV})$.

We performed sorption experiments of $\mathrm{Ce}(\mathrm{III})$ in different redox conditions (oxic and anoxic) onto a range of the minerals such as $\mathrm{FeOOH}, \mathrm{TiO}_{2}$, and $\mathrm{MnO}_{2}$. The route of redox reactions (including metal speciation and kinetics of the reaction) in these systems will be compared with the same systems containing $\mathrm{Pu}(\mathrm{III}, \mathrm{IV}, \mathrm{V}$ and VI).

This work was supported by the Russian Science Foundation (project 21-73-20083).

\section{References.}

1 A. Y. Romanchuk et al., Radiochim. Acta, 2016, 104, 843851.

2 A. Y. Romanchuk et al., Geochim. Cosmochim. Acta, 2013, 121, 29-40.

3 B. A. Powell et al. Environ. Sci. Technol., 2005, 39, $2107-$ 2114.

4 B. A. Powell et al., Environ. Sci. Technol., 2006, 40, 35083514. 